Bond University

Research Repository

\title{
Psychosocial interventions for pain management in older adults with dementia: A systematic review of randomized controlled trials
}

Pu, Lihui; Moyle, Wendy; Jones, Cindy; Todorovic, Michael

Published in:

Journal of Advanced Nursing

DOI:

10.1111/jan.13929

Licence:

Other

Link to output in Bond University research repository.

Recommended citation(APA):

Pu, L., Moyle, W., Jones, C., \& Todorovic, M. (2019). Psychosocial interventions for pain management in older adults with dementia: A systematic review of randomized controlled trials. Journal of Advanced Nursing, 75(8), 1608-1620. https://doi.org/10.1111/jan.13929

\section{General rights}

Copyright and moral rights for the publications made accessible in the public portal are retained by the authors and/or other copyright owners and it is a condition of accessing publications that users recognise and abide by the legal requirements associated with these rights.

For more information, or if you believe that this document breaches copyright, please contact the Bond University research repository coordinator. 
MS LIHUI PU (Orcid ID : 0000-0003-0136-0940)

DR CINDY JINGWEN JONES (Orcid ID : 0000-0002-7249-2580)

Article type : Review

Title Page

Psychosocial interventions for pain management in older adults with dementia: a systematic review of randomised controlled trials

Running head: Pain management in people with dementia

\section{Author details}

Lihui PU, RN, MSN, PhD Candidate, School of Nursing and Midwifery \& Menzies Health Institute Queensland, Griffith University, Australia

Wendy MOYLE, RN, Professor, PhD, School of Nursing and Midwifery \& Menzies Health Institute Queensland, Griffith University, Australia

Cindy JONES, Assistant Professor, PhD, Faculty of Health Sciences \& Medicine, Bond University, Australia \& Adjuct Member, Menzies Health Institute Queensland, Griffith University, Australia Michael TODOROVIC, Lecturer, PhD, School of Nursing and Midwifery \& Menzies Health Institute Queensland, Griffith University, Australia

This article has been accepted for publication and undergone full peer review but has not been through the copyediting, typesetting, pagination and proofreading process, which may lead to differences between this version and the Version of Record. Please cite this article as doi: 10.1111/jan.13929

This article is protected by copyright. All rights reserved. 


\section{Correspondence}

Lihui Pu, Menzies Health Institute Queensland, Griffith University, 2.18 Health Sciences (N48), 170

Kessel Rd, Nathan, Brisbane, Queensland, 4111, Australia.

E-mail: lihui.pu@griffithuni.edu.au

Twitter: @pu_lihui; @WendyMoyle2; @cindyjones_81; @MickeyTod

\section{Acknowledgments}

None.

\section{Conflict of Interest statement}

No conflict of interest has been declared by the author(s).

\section{Funding Statement}

This work was supported by a Ph.D. scholarship from Griffith University and the Chinese Scholarship Council (CSC).

\section{ABSTRACT}

Aim: To assess the effectiveness of psychosocial interventions on pain in older adults living with dementia.

Design: A systematic review with meta-analysis of randomised controlled trials.

This article is protected by copyright. All rights reserved. 
Data sources: Scopus, ProQuest, EBSCO (CINAHL and MEDLINE), PubMed, OVID (PsycINFO), Web of Science and Cochrane Library were searched from their inception up to 2 May 2018.

Review Methods: Risk of bias assessment and meta-analysis were conducted according to the Cochrane methods using RevMan 5.3 and findings were generated using the GRADE profiler software.

Results: Eight studies met the inclusion criteria, but the quality of the current evidence was low to moderate. Results showed that psychosocial interventions significantly reduced the observational pain score, as well as pain medication. Subgroup analyses indicated that sensory stimulation and individual interventions showed a reduction in observational pain in people with dementia.

Conclusion: Findings suggest that psychosocial interventions may be potentially effective alternatives for pain management in people with dementia. However, caution is needed in interpreting these results due to limited studies, risk of bias and heterogeneity across studies. Further, well-designed research is needed on psychosocial interventions to strengthen quality of pain management in people with dementia.

Impact: This review synthesized current evidence using psychosocial interventions to manage pain in people with dementia. Findings suggest that psychosocial interventions may lead to a potential reduction of pain and pain medication in people with dementia. Healthcare providers may wish to integrate psychosocial interventions as part of the multimodal approach to the management of pain in people living with dementia.

This article is protected by copyright. All rights reserved. 


\section{Key words}

pain, dementia, psychotherapy, psychosocial intervention, systematic review, meta-analysis, nursing, older adult, aged

\section{SUMMARY STATEMENT}

\section{Why is this review of the research needed?}

- Pain is prevalent in people with dementia and it is often under-detected and under-treated.

- Research studies have found psychosocial interventions to be effective for pain management in older adults, but people with dementia are often excluded from these studies.

- There is a paucity of evidence on the effectiveness of psychosocial interventions to manage pain in people with dementia.

\section{What are the key findings?}

- Psychosocial interventions may potentially reduce pain and pain medication in people with dementia.

- This review indicates that there were insufficient rigorous studies to support the potential use of psychosocial interventions to manage pain in people with dementia.

- Large variations in pain measurements suggest the need for guidelines and consensus on pain assessment tools for people with dementia.

\section{How should the findings be used to influence research/ practice/ policy/ education?}

- More randomised controlled trials with larger sample sizes and rigorous study designs are needed to explore the effectiveness of psychosocial interventions to manage pain in people with dementia.

This article is protected by copyright. All rights reserved. 
- The model of delivery, content and/or duration of psychosocial interventions should be tailored to individual preferences and cultural background, as well as programmed into daily clinical practice.

- More research is needed to develop appropriate pain assessment tools with sensitivity in detecting treatment effects on pain in people with dementia.

\section{INTRODUCTION}

Studies show that pain is one of the most common problems in people with dementia, affecting approximately half of nursing home residents with dementia (Lee, McConnell, Knafl, \& Algase, 2015; van Kooten, Smalbrugge, van der Wouden, Stek, \& Hertogh, 2017) and up to $57.3 \%$ of people with dementia living in the community (Barry, Parsons, Passmore, \& Hughes, 2016). Such high rates of pain in people with dementia is known to be closely associated with the presentation of neuropsychiatric symptoms, as well as reduced sleep quality and poor quality of life (Hodgson, Gitlin, \& Jin, 2014; Rajkumar et al., 2017). However, there remains a paucity of evidence for pain management strategies in dementia (Husebo, Achterberg and Flo, 2016). Indeed, only three out of fifteen existing pain management guidelines are designed for use with people with dementia and robust evidence of effective interventions for this population are lacking (Corbett et al., (2016). In light of this, more evidence-based research is warranted to better understand the quality of pain care for people with dementia (de Tommaso, Kunz, \& Valeriani, 2017; McGuire, Nicholas, Asghari, Wood, \& Main, 2014; Savvas \& Gibson, 2015).

Specifically, cognitive impairment and communication difficulties can make the detection and management of pain challenging in this population and nonverbal expressions of pain (i.e., facial grimacing and behavioural changes) can often go under-recognised (Booker, 2016) and lead to inappropriate use of antipsychotic medication (Rajkumar et al., 2017) and reduced rates of analgesic

This article is protected by copyright. All rights reserved. 
use (Liu \& Leung, 2017; Malara et al., 2016). Although people with dementia may receive less pain medication than their counterparts, analgesics (opioids, antipyretics, anticonvulsants and nonsteroidal anti-inflammatory drugs) may have serious side effects including constipation, confusion, falls and personality changes, which may be more troublesome than the pain (Cazacu et al., 2015; Dowell, Haegerich, \& Chou, 2016). As such, the Centres for Disease Control (CDC) suggest psychosocial interventions, such as music and physical activity, may be helpful to manage pain in older adults (Guerriero \& Reid, 2017).

\section{Background}

Psychosocial interventions are often discussed synonymously with non-pharmacological interventions, although the two terms are different. In this review, psychosocial interventions are defined according to the INTERDEM Network (Moniz-Cook, Vernooij-Dassen, Woods, \& Orrell, 2011) as physical, cognitive, or social activities that aim to improve wellbeing and functioning of the person with dementia. Non-pharmacological interventions, according to McDermott et al. (2018), do not clearly describe what a non-pharmacological intervention is and simply define the intervention as not involving medications. Further, non-pharmacological interventions tend to focus on symptom management whereas psychosocial interventions have a broad focus on functioning and wellbeing.

Pain has an impact on psychological and social functioning. The integrated biopsychosocial model of pain and dementia supports the application of psychosocial interventions to manipulate the psychological and/or social components of pain to modify the pain experience in people with dementia (Gagliese, Gauthier, Narain, \& Freedman, 2017; Gatchel, Peng, Peters, Fuchs, \& Turk, 2007). The underlying mechanism may be attributed to the strategy of distracting attention from pain when people are participating in another sensory modality (such as an auditory, visual or tactile stimulus), accompanied by a sense of relaxation (Jensen, 2011; Johnson, 2005; Park, Chun, \& Gang,

This article is protected by copyright. All rights reserved. 
2015). Additionally, psychosocial interventions can also help to stimulate the release of pain modulating neurotransmitters, such as noradrenaline, serotonin, or endogenous opiates, which may moderate the pain system (Melzack, 2001).

Previous reviews have suggested that psychosocial interventions can alleviate pain for long-term care (LTC) residents with fewer side-effects and can be more cost-effective when compared to analgesic medication (Keefe, Porter, Somers, Shelby, \& Wren, 2013; Tederko, Krasuski, \& Szczypiorowska, 2014). Psychcosocial interventions can also help reduce agitation (Pedersen andersen, Lugo andreassen, \& Sütterlin, 2017), distress (Mitchell \& Agnelli, 2015), anxiety and depression (Orgeta, Qazi, Spector, \& Orrell, 2015) in people with dementia. However, the effectiveness of psychosocial interventions on pain in people with dementia is still unclear. Results from current pain reviews have often included people with and without dementia (Keefe et al., 2013; Knopp-Sihota, Patel, \& Estabrooks, 2016), which impedes generalisation of the results to people with dementia specifically. The reduced level of cognitive function and inability to verbalise by people with dementia may influence their ability to understand and participate in activities, which makes implementation and outcome measurement more complex than those without dementia. Existing reviews based on both randomised and non-randomised trials (Knopp-Sihota et al., 2016; Park \& Hughes, 2012) have provided the knowledge basis and potential application of psychosocial interventions to manage pain in older adults. However, a systematic review of RCTs can provide more reliable conclusions and avoid possible confounding factors. In addition, previous reviews have only focused on older adults from a specific setting, such as community (Park \& Hughes, 2012) or nursing homes (Anderson, Deng, Anthony, Atalla, \& Monroe, 2017; Knopp-Sihota et al., 2016; Tederko et al., 2014), which also limits the generalisation of the results to a larger population.

This article is protected by copyright. All rights reserved. 
Despite the fact that pain is highly prevalent and often undertreated due to the lack of knowledge and barriers in pain assessment and management in people with dementia, there is a lack of evidence to guide the use of psychosocial interventions to manage pain in this group. This paper aims to provide an overview of the available evidence from RCTs to explore the effectiveness of psychosocial interventions as supportive modalities to manage pain, with a particular focus on people living with dementia in any setting.

\section{THE REVIEW}

\section{Aims}

This review aimed to provide an overview of the available evidence from RCTs and to assess the effectiveness of psychosocial interventions for managing pain in people with dementia.

\section{Design}

This was a quantitative systematic review with meta-analyses following the Cochrane methods (Higgins \& Green, 2011) and the standard guidelines of Preferred Reporting Items for Systematic Reviews and Meta-Analyses (PRISMA) (Moher, Liberati, Tetzlaff, \& Altman, 2009). It was prospectively registered with PROSPERO, the International Prospective Register of Systematic Reviews (registration number: CRD 42018090534).

\section{Search methods}

Seven electronic databases were searched, including Scopus, ProQuest, EBSCO (CINAHL and Medline), PubMed, OVID (PsycINFO), Web of Science and Cochrane Library. Each database was searched from their inception to November 2017 and updated database searches were undertaken on May 2, 2018 to capture new available research. Medical Subject Headings (MeSH) included

This article is protected by copyright. All rights reserved. 
"dementia", "pain" and "psychotherapy". Key words searches were performed on abstracts using Boolean. Search terms were organised into three groups, including:

Population: dementia OR Alzheimer's OR "cognitive impairment" OR "memory loss" OR "cognitive decline" OR "mild cognitive impairment" OR "cognitive function" OR "cognitive dysfunction" OR "cognitive disability"

Intervention: "psychosocial therapy" OR nonpharmacological OR non-pharmacological OR psychotherapy OR animal OR pet OR doll OR music OR games OR movies OR picture OR humo* OR Snoezelen OR aromatherapy OR reminiscence OR reiki OR therapeutic touch OR reflexology OR massage OR imagery OR meditation OR "Tai Ji" OR "qi gong" OR breath* OR "sensory therapy" OR "cognitive behavio* therapy" OR horticultural OR garden

Outcomes: pain OR discomfort OR distress OR suffering OR "pain management" OR "pain relief" OR "pain medication" OR analgesics

The search strategy in EBSCO is shown in Table S1. Reference checks were conducted for retrieved articles to capture relevant publications. Titles and abstracts were then screened and potentially relevant citations with full texts were assessed independently by two reviewers (LP \& CJ) to determine eligibility for inclusion. Any disagreements were resolved through discussion, or with a third reviewer.

This article is protected by copyright. All rights reserved. 
To be included in the review, selected studies had to meet the following inclusion criteria: (1)

Participants: older adults ( $\geq 60$ years old) with dementia or mild cognitive impairment living in any setting (e.g., LTC, community); (2) Design: randomised controlled trials (RCTs); (3) Intervention: psychosocial interventions versus control groups with no treatment, usual standard care, or an alternative intervention; (4) Outcomes: primary outcomes focused on levels of pain, as measured by validated self- or proxy-reported scales, or observational pain scales rated by a researcher, staff or family members. The secondary outcome was the use of pain medication; and (5) original research published in the English language. Studies were excluded if they focused on interventions for care staff or family caregivers.

\section{Search outcome}

The seven database searches yielded a total of 7,186 records, with an additional seven citations included from reference checks. After removing duplicates, 4,933 records were screened by title and abstract, which resulted in 68 full-texts assessed for eligibility. A total of nine articles from eight RCTs met the inclusion criteria. The study flow diagram is shown in Figure 1.

\section{Quality appraisal}

Quality appraisal of the eight included studies was based on the Cochrane Collaboration's tool for assessing risk of bias in randomised trials (Higgins et al., 2011). The six criteria for risk of bias included: random sequence generation (selection bias); allocation concealment (selection bias); blinding of participants and personnel (performance bias); blinding of outcome assessment (detection bias); incomplete outcome data (attrition bias); selective reporting (reporting bias); and other bias. Two reviewers (LP \& CJ) independently assessed the quality of each study according to the Cochrane Handbook for Systematic Reviews of Interventions, version 5.1.0, Chapter 8 (Higgins \& Green, 2011) and any disagreements were resolved through discussion with a third reviewer (WM).

This article is protected by copyright. All rights reserved. 
The quality of evidence for specific outcomes was assessed according to the Grading of Recommendations, Assessment, Development and Evaluation (GRADE) approach (GRADE Working Group, 2012).

\section{Data abstraction}

All data were extracted using a purposefully designed, standard data extraction form. Items included details about: (1) study characteristics (e.g., source, country, study design, setting); (2) participants (e.g., age, sample size, drop-out rate, stage of dementia, history of pain); (3) intervention characteristics (e.g., type, instructor, length, frequency, duration and control conditions); (4) outcomes (measurement for pain, type of measurement, pain medication, adverse events); and (5) findings of the included studies.

\section{Synthesis}

Data were combined and statistically analysed using a meta-analysis procedure in RevMan 5.3

(Higgins \& Green, 2011). Overall results of the review were presented in a summary of findings table, which was generated with the GRADE profiler software (GRADEpro) (GRADE Working Group, 2012). Generated pooled estimates on continuous data (e.g., scores on pain scales) were calculated with the mean difference (MD) or standard mean difference (SMD), with 95\% confidence interval (CI). A random-effect model was applied to pool the data due to the potential heterogeneity across studies measured by chi-square test $\left(P<.10\right.$ and $\left.I^{2}>40 \%\right)$. Subgroup analyses were performed on outcome measures, types/format of interventions, degree of cognitive impairment and pain history of participants, where possible. Sensitivity analyses were applied to validate the rationality and reliability of the results and the funnel plot was used to detect publication bias. Outcomes unable to be pooled in the meta-analysis were presented with a narrative description.

This article is protected by copyright. All rights reserved. 


\section{RESULTS}

\section{Participants and study characteristics}

This review included RCTs with the following designs: three parallel, two cross-over, one cluster, one multi-arm and one cluster-study with multi-arm. Half of the studies were undertaken in the USA (50\%) and one each from the Netherlands, Australia, France and Spain. The care recipients were residing in LTC facilities in six studies, while one study was conducted in the community (Tsai, Chang, Beck, Kuo, \& Keefe, 2013) and one recruited participants from memory clinics (Pongan et al., 2017). The sample size was typically small (range 10 129), with the highest drop-out rate being 18.2\%. Participants with different stages of dementia (mild, moderate or advanced dementia) and different types of pain history (chronic pain, cancer pain or unclear pain) at baseline, were recruited. Characteristics of participants are presented in Table S2.

Different types of psychosocial interventions were identified. Six studies focused on sensory stimulation - reflexology (Hodgson \& Andersen, 2008), massage (Hodgson \& Lafferty, 2012; Kapoor \& Orr, 2017), ear acupressure (Rodriguez-Mansilla et al., 2015), music (Pongan et al., 2017) and showering (Sloane et al., 2004) - whereas two studies reported physical activity interventions, including Tai Chi (Tsai et al., 2013) and passive movement therapy (PMT) (Hobbelen, Tan, Verhey, Koopmans, \& de Bie, 2012). The format of the interventions included both group and individual interventions and the frequency of interventions ranged from once a week to daily, with 10 to 120 minutes per session and spanning a period of four to 20 weeks. Characteristics of participants and the studies are presented in Tables S2 and S3.

This article is protected by copyright. All rights reserved. 


\section{Outcomes measurements}

Pain was measured by several observational as well as self-reported pain scales, including: the Pain Assessment Checklist for Seniors with Limited Ability to Communicate (PACSLAC) (Hobbelen et al., 2012); Checklist of Nonverbal Pain Indicators (CNPI) (Hodgson \& Andersen, 2008; Hodgson \& Lafferty, 2012); Pain Assessment in Advanced Dementia (PAINAD) (Kapoor \& Orr, 2017); Brief Pain Inventory (BPI) (Pongan et al., 2017); DOLOPLUS-2 scale (Rodriguez-Mansilla et al., 2015); Discomfort Scale for Dementia of the Alzheimer Type (DS-DAT) (Sloane et al., 2004); and the Western Ontario and McMaster Universities Osteoarthritis Index (WOMAC) pain subscale and observation of videotaped pain behaviour (Tsai et al., 2015). Self-reported scales included the Numeric Rating Scale (NRS), Simple Visual Scale (SVS) (Pongan et al., 2017) and Verbal Descriptive Scale (VDS) (Tsai et al., 2015). Tsai et al. (2015) further calculated doses of analgesic medication based on the calculation of standard acetaminophen equivalents and three studies measured percentages of medication use (Hobbelen et al., 2012; Hodgson \& Andersen, 2008; Sloane et al., 2004).

\section{Risk of bias}

Risk of bias is presented in Figures 2 and S1. Four studies reported the randomisation methods, which included a computer-generated random list (Hobbelen et al., 2012; Rodriguez-Mansilla et al., 2015), random number table conducted by an independent researcher statistician (Tsai et al., 2013), or another independent researcher (Pongan et al., 2017). Only two studies provided sufficient information for allocation concealment and blinding of the participants (Rodriguez-Mansilla et al., 2015; Tsai et al., 2013). Blinding of outcome assessors (detection bias) was reported in seven studies and blinding was unclear in one study (Kapoor \& Orr, 2017). Three trials reported an intention-totreat (ITT) analysis (Hodgson \& Andersen, 2008; Pongan et al., 2017; Tsai et al., 2013) and one study reported no drop-out during the study (Hodgson \& Lafferty, 2012). As for other bias, Sloane et al. (2004) reported imbalance between intervention and control groups at baseline and there was

This article is protected by copyright. All rights reserved. 
insufficient information about the baseline difference in three studies (Hodgson \& Lafferty, 2012;

Kapoor \& Orr, 2017; Rodriguez-Mansilla et al., 2015). Regarding data analysis, one cluster trial failed to report the intra-cluster correlation coefficient (ICC) to adjust for the effect of clustering (Sloane et al., 2004).

\section{The effectiveness of psychosocial interventions for pain relief in people with dementia}

\section{Statistical analysis}

Generated pooled estimates on the effectiveness of psychosocial interventions on pain were calculated with standard mean differences (SMDs) (Guyatt et al., 2013), due to the heterogeneity of the pain scales. Subgroup analyses were performed based on the measurement of pain (observational or self-reported pain), types of interventions (sensory stimulation or physical activity), as well as intervention format (group or individual). However, subgroup analysis was not viable on the level of cognitive impairment or the pain history of participants on key outcomes. For data imputation, results from two intervention groups were combined to create a single pair-wise comparison (Higgins \& Green, 2011) from two multi-arm RCTs (Rodriguez-Mansilla et al., 2015; Sloane et al., 2004). The sample sizes from two cross-over RCTs were imputed as double (Hodgson \& Andersen, 2008; Hodgson \& Lafferty, 2012) as each patient appeared twice in the trial (Elbourne et al., 2002). We analysed data with the available results from one cluster-RCT due to insufficient information for ICC for data imputation (Sloane et al., 2004). Results concerning pain medication and adverse events are presented in a narrative description. No publication bias was detected. Summary of the findings is shown in Table 1.

This article is protected by copyright. All rights reserved. 


\section{Different outcome measurements}

Analysis showed that the effectiveness of psychosocial interventions on observational pain was statistically significant $(\mathrm{SMD}=-0.48,95 \% \mathrm{Cl}[-0.85,-0.10])$; however, the certainty of the evidence was very low. No significant result was found for self-reported pain (SMD $=-0.27,95 \% \mathrm{Cl}[-0.57$, 0.03]) (Figure 3).

\section{Different types of psychosocial interventions}

Analysis showed that sensory stimulation significantly reduced observational pain in people with dementia (SMD $=-0.58,95 \% \mathrm{Cl}[-0.99,-0.17]$, very low certainty), but there was no significant result for physical activity interventions (SMD $=-0.24,95 \% \mathrm{Cl}[-1.06,0.59])$ (Figure 4).

\section{Different format of psychosocial interventions}

A significant result on observational pain was found for individual interventions (SMD =

$-0.55,95 \% \mathrm{Cl}[-1.01,-0.09]$, very low certainty), while there was no significant result for group interventions $(\mathrm{SMD}=-0.27,95 \% \mathrm{Cl}[-1.06,0.53])$ (Figure 5). Participants receiving individual interventions were recruited from nursing homes.

\section{Sensitive analysis}

The effectiveness of psychosocial interventions on pain in people with dementia did not achieve statistical significance for observational pain $(\mathrm{SMD}=-0.42,95 \% \mathrm{Cl}[-0.86,0.01])$, sensory stimulation interventions $(\mathrm{SMD}=-0.53,95 \% \mathrm{Cl}[-1.07,0.01])$, or individual interventions $(\mathrm{SMD}=-0.51,95 \% \mathrm{Cl}[-$ $1.11,0.10]$ ) when two studies with high risks of bias were omitted (Kapoor \& Orr, 2017; Sloane et al., 2004).

This article is protected by copyright. All rights reserved. 


\section{The effectiveness of psychosocial interventions in reducing pain medications}

Only one study provided adequate information about the change of analgesic use before and after the intervention (Tsai et al., 2015). Although no significant difference was found in daily acetaminophen equivalent dosage between two groups at post-test $(P=0.308)$, analgesic intake in the Tai Chi group was reduced ( $223 \mathrm{mg} /$ day), whereas there was an increase in the comparator attention control group $(221.7 \mathrm{mg} /$ day $)$. The change in analgesic intake after intervention was insufficiently reported in two studies, despite comparable analgesic use at baseline (Hobbelen et al., 2012; Sloane et al., 2004). Hodgson and Andersen (2008) reported no change in medications for the intervention and control groups. No detailed information about medication use was available for meta-analysis.

\section{Adverse events}

Five studies reported no adverse events during the study period (Hodgson \& Andersen, 2008; Hodgson \& Lafferty, 2012; Kapoor \& Orr, 2017; Sloane et al., 2004; Tsai et al., 2013).

\section{DISCUSSION}

To our knowledge, this is the first systematic review and meta-analysis of RCTs to examine the effectiveness of psychosocial interventions on pain in people with dementia. Eight studies were included in this review and results indicate that psychosocial interventions significantly reduced observed pain in people with dementia. Further, subgroup analyses showed that sensory stimulation interventions (e.g., massage, reflexology, acupressure and music) and individual format of intervention significantly reduced observational pain in people with dementia. However, sensitivity analyses suggest that our estimates are not robust based on the current studies.

This article is protected by copyright. All rights reserved. 


\section{Comparison with previous literature}

Findings from this meta-analysis concur with a recent review involving seven quantitative studies using complementary and alternative medicine (CAM) for residents with dementia living in LTC (Anderson et al., 2017). While results from three of the included studies indicated a reduction of pain in people with dementia, it is important to note that only CAM therapies assessed in RCTs were included and the risk of bias and quality of the evidence was unclear. In another review that included ten studies with psychosocial interventions, lower pain intensity was reported in seven studies, involving interventions such as listening to music, guided imagery, mindfulness-based meditation and cognitive-behavioural therapy (Park \& Hughes, 2012). However, both people with and without cognitive impairment were included in the review and no subgroup analysis of results was conducted for people with cognitive impairment, making comparisons of results difficult. Similarly, while Tederko et al. (2014) found that non-pharmacological pain therapies could have a possible positive analgesic effect for LTC residents, effectiveness remains unproven due to the low methodological quality of the included studies. In contrast, a systematic review and meta-analysis found no statistical differences in treatment effect $(S M D=0.30,95 \% \mathrm{Cl}[-0.60,0.01])$ of non-analgesic interventions (e.g., humorous movie, mindfulness-based stress reduction, acupuncture, social visits, exercise) on pain in nursing home residents (Knopp-Sihota et al., 2016). This review, however, permitted inclusion of non-randomised studies (e.g., before-and-after studies without a control group) and did not undertake any subgroup analyses of residents with dementia.

Our subgroup analyses indicated that sensory stimulation showed a significant reduction in observational pain in people with dementia. This may be explained by positive emotion arousal (Jensen, 2011) and the release of neuromodulatory chemicals, such as noradrenaline, serotonin, or endogenous opiates (Field, 2018). These biochemical responses have previously shown to modulate pain at the spinal cord level in the ascending pathway, as well as at the brainstem in the descending

This article is protected by copyright. All rights reserved. 
pathway (Bushnell, Ceko, \& Low, 2013; Melzack, 2001). As only two studies using physical activities were included in this review, no significant result was found for pain reduction. However, potential underlying mechanisms have been explored for the effects of physical activities to relieve pain through the release of endogenous opiates, as well as the elimination of muscular tension (Rhoads, 2013). Results from this review indicate that sensory stimulation interventions were focused on chronic pain, while physical activities were specifically focused on pain related to paratonia or osteoarthritis. However, it is difficult to generalise these results due to the limited number of studies and diversity in the pain experience of participants. In addition, further clinical and laboratory studies concerning the hypothetical mechanism of pain modulation on the nervous system are warranted.

Of the eight studies included in our review, only one compared the analgesic consumption between Tai Chi and an attention control group and showed a promising decrease of analgesics for Tai Chi (Tsai et al., 2015). Given the high prevalence of pain in older adults, it is common for them to take analgesic medications for long periods of time. It is, therefore, important to document and compare medication use (e.g., the name of the analgesic they were taking, regular or Pro Re Nata (PRN), the dosage and the frequency of use) between groups, as concomitant medication consumption may confound the results on pain experience. Other confounding methods, such as physiotherapies, should also be fully documented.

\section{Heterogeneous groups of participants and outcome measurement}

People with different stages of dementia and levels of pain, as well as a variety of outcome measures, were reported in this review. Although subgroup analysis with a random effect model and SMD was applied to synthesise and standardise the effect estimation of outcomes using different scales, statistical heterogeneity was high $\left(I^{2}>40 \%\right)$. This may be explained by variations in the

This article is protected by copyright. All rights reserved. 
interventions, as well as pain history of participants. That said, however, generalisation of the results should be treated with caution, as heterogeneous participants may lead to a large SD with a small SMD and, thus, bias the absolute estimate of the magnitude of intervention effect (Guyatt et al., 2013).

In terms of the effect of psychosocial interventions on pain in participants from different settings, the review indicates that individual psychosocial interventions may lead to a potential pain reduction in people with dementia living in nursing homes. Effects of such interventions for people living in communities, however, are not clear and more research is needed.

Regarding pain assessment in people with dementia, there is currently no consensus on the best tool to assess pain in people with dementia. Pain measurement instruments for people with dementia should be based on the person's level of cognitive impairment and, based on previous studies, individual self-reports of pain should be obtained whenever possible (Herr, Coyne, McCaffery, Manworren, \& Merkel, 2011). When self-reports are unattainable or absent, observation of painrelated behaviours from family caregivers or health care providers offer alternate ways for pain assessment (Ersek, Polissar, \& Neradilek, 2011). The recent UK National Guidelines for Assessment of Pain in Older People recommended NRS or verbal descriptors as self-reports for people with mild to moderate cognitive impairment. For those with advanced dementia, PAINAD or Doloplus-2 can be used as observational measures of pain (Schofield, 2018). In this case, the inter-rater reliability with multiple observers should be demonstrated. Furthermore, the use of innovative technology to detect pain in older adults with dementia is also ongoing, such as the Facial Action Coding System (FACS) (Lints-Martindale, Hadjistavropoulos, Barber, \& Gibson, 2007) and the electronic Pain Assessment Tool (ePAT) (Atee, Hoti, Parsons, \& Hughes, 2017).

This article is protected by copyright. All rights reserved. 
Current guidelines recommend that the same principles of pain management apply equally to people with and without dementia and that psychosocial interventions, such as music therapy, exercise or relaxation, are considered useful to reduce pain in people with dementia (Cornally et al., 2016; Guideline Adaptation Committee, 2016). These recommendations are based on expert opinions and there is an absence of evidence-based guidelines for practice (Corbett et al., 2016). Findings from this systematic review of RCTs potentially could provide the opportunity to inform clinical practice in regards to pain management in people with dementia.

\section{The validity of the evidence based on quality assessment}

Given the lack of published empirical studies, only a small number of studies met the inclusion criteria and the poor quality of the evidence lowers our confidence in the effect estimate. Caution is needed in generalising findings to a broader population in clinical practice due to the following reasons: (1) available RCTs had low to moderate quality, in particular, potential selection bias and attrition bias cannot be ruled out; (2) results from the sensitivity analysis also indicated that the evidence of the effectiveness of psychosocial interventions on pain was not robust and consistent, based on the current available studies; and (3) different characteristics of participants and interventions lead large heterogeneity of results and inconsistency across the studies. As such, more RCTs, of higher quality and involving participants with more homogeneity, are needed to help identify the reliability and validity of the results and generalise the findings to the target population.

\section{Limitations}

Given the lack of published empirical evidence, only a small number of studies met the inclusion criteria and the sample size of the included studies is relatively small, such that our findings may not be applicable to other settings. Although favourable results were achieved from the meta-analysis, they were not consistent after sensitivity analysis and the risk of bias of included studies was rated

This article is protected by copyright. All rights reserved. 
as unclear or high. Conclusions should be interpreted with caution due to the large variation in participant characteristics, interventions and outcome measurements, which precludes the generalisation of the results to a specific group. In addition, two cross-over studies were included in this review, although this design is not recommended for dementia care due to the progressive deterioration of the condition. Finally, only articles published in English were included and thus, research reported in other languages, particularly studies about Tai Chi or massage, may have been missed.

\section{Recommendations for future research and practice}

Several recommendations for future research can be made from this review. First, the model of delivery, content and/or duration of psychosocial interventions should be tailored to individual preferences and cultural background, as well as programmed into daily clinical practice, which will improve attendance and adherence to the intervention. Second, different outcome measures used in the included studies contributed to the inconsistency of the results and limited the quality of the evidence. Therefore, follow-up studies are warranted to develop appropriate pain assessment tools with diverse samples and further studies of tool sensitivity to detect changes in response to interventions are needed. Third, there is concern regarding insufficient reporting of participants' safety during the intervention. Given that some of the interventions are associated with side-effects, such as injury or allergic responses, future studies should assess and report safety issues. Finally, further understanding of the theoretical background of the mechanism for psychosocial interventions on pain in people with dementia is required.

This article is protected by copyright. All rights reserved. 


\section{CONCLUSION}

This review examined RCTs investigating the effectiveness of psychosocial interventions on pain in older adults with dementia. Evidence suggests that psychosocial interventions may lead to a potential reduction of pain and pain medication in people with dementia. However, results should be interpreted with caution due to low to moderate methodology quality, heterogeneity of participants, intervention approaches and variations in outcome measurements. This review highlights the paucity of rigorous research about pain management in people with dementia and the need for future studies to focus on psychosocial interventions in contributing to the effective management of pain in this vulnerable population.

\section{Conflict of Interest Statement}

No conflict of interest has been declared by the authors.

\section{Author Contributions}

All authors have agreed on the final version and meet at least one of the following criteria (recommended by the ICMJE*):

1) substantial contributions to conception and design, acquisition of data, or analysis and interpretation of data;

2) drafting the article or revising it critically for important intellectual content.

* http://www.icmje.org/recommendations/

This article is protected by copyright. All rights reserved. 


\section{References}

Anderson, A. R., Deng, J., Anthony, R. S., Atalla, S. A., \& Monroe, T. B. (2017). Using complementary and alternative medicine to treat pain and agitation in dementia: A review of randomized controlled trials from long-term care with potential use in critical care. Critical Care Nursing Clinics of North America, 29(4), 519-537. doi:10.1016/j.cnc.2017.08.010

Atee, M., Hoti, K., Parsons, R., \& Hughes, J. D. (2017). Pain assessment in dementia: Evaluation of a point-of-care technological solution. Journal of Alzheimer's Disease, 60(1), 137-150. doi:10.3233/JAD-170375

Barry, H. E., Parsons, C., Passmore, A. P., \& Hughes, C. M. (2016). Exploring the prevalence of and factors associated with pain: A cross-sectional study of community-dwelling people with dementia. Health \& Social Care in the Community, 24(3), 270-282. doi:10.1111/hsc.12204

Booker, S. Q. (2016). Assessing pain in nonverbal older adults. Nursing, 46(5), 66-69. doi:10.1097/01.NURSE.0000480619.08039.50

Bushnell, M. C., Ceko, M., \& Low, L. A. (2013). Cognitive and emotional control of pain and its disruption in chronic pain. Nature Reviews Neuroscience, 14(7), 502-511. doi:10.1038/nrn3516

Cazacu, I., Miremont-Salamé, G., Mogosan, C., Fourrier-Réglat, A., Loghin, F., \& Haramburu, F. (2015). Preventability of adverse effects of analgesics: Analysis of spontaneous reports. European Journal of Clinical Pharmacology, 71(5), 625-629. doi:10.1007/s00228-015-1829-8

Corbett, A., Nunez, K.-M., Smeaton, E., Testad, I., Thomas, A. J., Closs, S. J., . . Lawrence, V. (2016). The landscape of pain management in people with dementia living in care homes: A mixed methods study. International Journal of Geriatric Psychiatry, 31(12), 1354-1370. doi:10.1002/gps.4445

This article is protected by copyright. All rights reserved. 
Cornally, N., McLoughlin, K., Coffey, A., Weathers, E., Buckley, C., Mannix, M., ... Timmons, S. Palliative care for the person with dementia guidance document 5: Pain assessment and management. Available from http://hospicefoundation.ie/wpcontent/uploads/2016/11/Final-Guidance-Document-5-Pain.pdf

de Tommaso, M., Kunz, M., \& Valeriani, M. (2017). Therapeutic approach to pain in neurodegenerative diseases: Current evidence and perspectives. Expert Review of Neurotherapeutics, 17(2), 143-153. doi:10.1080/14737175.2016.1210512

Dowell, D., Haegerich, T. M., \& Chou, R. (2016). CDC guideline for prescribing opioids for chronic pain-United States, 2016. JAMA, 315(15), 1624-1645. doi:10.1001/jama.2016.1464

Elbourne, D. R., Altman, D. G., Higgins, J. P. T., Curtin, F., Worthington, H. V., \& Vail, A. (2002). Metaanalyses involving cross-over trials: Methodological issues. International Journal of Epidemiology, 31(1), 140-149. doi:10.1093/ije/31.1.140

Ersek, M., Polissar, N., \& Neradilek, M. B. (2011). Development of a composite pain measure for persons with advanced dementia: Exploratory analyses in self-reporting nursing home residents. Journal of Pain \& Symptom Management, 41(3), 566-579. doi:10.1016/j.jpainsymman.2010.06.009

Field, T. (2018). Pain and massage therapy: A narrative review. Current Research in Complementary \& Alternative Medicine, CRCAM-125. doi:10.29011/CRCAM-125/100025

Gagliese, L., Gauthier, L. R., Narain, N., \& Freedman, T. (2017). Pain, aging and dementia: Towards a biopsychosocial model. Progress in Neuro-Psychopharmacology and Biological Psychiatry. doi:10.1016/j.pnpbp.2017.09.022 [Epub ahead of print]

Gatchel, R. J., Peng, Y. B., Peters, M. L., Fuchs, P. N., \& Turk, D. C. (2007). The biopsychosocial approach to chronic pain: Scientific advances and future directions. Psychological Bulletin, 133(4), 581-624. doi:10.1037/0033-2909.133.4.581

This article is protected by copyright. All rights reserved. 
GRADE Working Group. The grading of recommendations assessment, development and evaluation (GRADE) working group website. 2011. Available from http://gradeworkinggroup.org/

Guerriero, F., \& Reid, M. C. (2017). New opioid prescribing guidelines released in the us: What impact will they have in the care of older patients with persistent pain? Current Medical Research \& Opinion, 33(2), 275-278. doi:10.1080/03007995.2016.1254603

Guideline Adaptation Committee. Clinical practice guidelines and principles of care for people with dementia. Sydney. Guideline adaptation committee; 2016. Available from http://sydney.edu.au/medicine/cdpc/documents/resources/Dementia-GuidelineRecommendations-WEB-version.pdf

Guyatt, G. H., Thorlund, K., Oxman, A. D., Walter, S. D., Patrick, D., Furukawa, T. A., . . Schunemann, H. J. (2013). GRADE guidelines: 13. Preparing summary of findings tables and evidence profiles-continuous outcomes. Journal of Clinical Epidemiology, 66(2), 173-183. doi:https://doi.org/10.1016/j.jclinepi.2012.08.001

Herr, K., Coyne, P. J., McCaffery, M., Manworren, R., \& Merkel, S. (2011). Pain assessment in the patient unable to self-report: Position statement with clinical practice recommendations. Pain Management Nursing, 12(4), 230-250. doi:10.1016/j.pmn.2011.10.002

Higgins, J. P., Altman, D. G., Gøtzsche, P. C., Jüni, P., Moher, D., Oxman, A. D., . . Sterne, J. A. (2011). The cochrane collaboration's tool for assessing risk of bias in randomised trials. BMJ, 343 , d5928. doi:10.1136/bmj.d5928

Higgins, J. P., \& Green, S. (editors). Cochrane handbook for systematic reviews of interventions Version 5.1.0. [updated March 2011]. The Cochrane Collaboration, 2011. Retrieved from www.handbook.cochrane.org

This article is protected by copyright. All rights reserved. 
Hobbelen, J. H. S., Tan, F. E., Verhey, F. R., Koopmans, R. T., \& de Bie, R. A. (2012). Passive movement therapy in severe paratonia: A multicenter randomized clinical trial. International Psychogeriatrics, 24(05), 834-844. doi: 10.1017/S1041610211002468

Hodgson, N., Gitlin, L. N., \& Jin, H. (2014). The influence of sleep disruption and pain perception on indicators of quality of life in individuals living with dementia at home. Geriatric Nursing, 35(5), 394-398. doi:10.1016/j.gerinurse.2014.08.005

Hodgson, N. A., \& Andersen, S. (2008). The clinical efficacy of reflexology in nursing home residents with dementia. The Journal of Alternative and Complementary Medicine, 14(3), 269-275. doi:10.1089/acm.2007.0577

Hodgson, N. A., \& Lafferty, D. (2012). Reflexology versus Swedish massage to reduce physiologic stress and pain and improve mood in nursing home residents with cancer: A pilot trial. Evidence-Based Complementary and Alternative Medicine, 456897. doi:10.4103/09702113.99113

Husebo, B. S., Achterberg, W., \& Flo, E. (2016). Identifying and managing pain in people with alzheimer's disease and other types of dementia: A systematic review. CNS Drugs, 30(6), 481-497. doi:10.1007/s40263-016-0342-7

Jensen, M. P. (2011). Psychosocial approaches to pain management: An organizational framework. Pain, 152(4), 717-725. doi:10.1016/j.pain.2010.09.002

Johnson, M. H. (2005). How does distraction work in the management of pain? Current Pain and Headache Reports, 9(2), 90-95.

Kapoor, Y., \& Orr, R. (2017). Effect of therapeutic massage on pain in patients with dementia. Dementia, 16(1), 119-125. doi:10.1177/1471301215583391

This article is protected by copyright. All rights reserved. 
Keefe, F. J., Porter, L., Somers, T., Shelby, R., \& Wren, A. V. (2013). Psychosocial interventions for managing pain in older adults: Outcomes and clinical implications. British Journal of Anaesthesia, 111(1), 89-94. doi:10.1093/bja/aet129

Knopp-Sihota, J. A., Patel, P., \& Estabrooks, C. A. (2016). Interventions for the treatment of pain in nursing home residents: A systematic review and meta-analysis. Journal of the American Medical Directors Association, 17(12), 1163.e1119-1163.e1128. doi:10.1016/j.jamda.2016.09.016

Lee, K. H., McConnell, E. S., Knafl, G. J., \& Algase, D. L. (2015). Pain and psychological well-being among people with dementia in long-term care. Pain Medicine, 16(6), 1083-1089. doi:10.1111/pme.12739

Lints-Martindale, A. C., Hadjistavropoulos, T., Barber, B., \& Gibson, S. J. (2007). A psychophysical investigation of the facial action coding system as an index of pain variability among older adults with and without alzheimer's disease. Pain Medicine, 8(8), 678-689. doi:10.1111/j.1526-4637.2007.00358.x

Liu, J. Y. W., \& Leung, D. Y. P. (2017). Pain treatments for nursing home residents with advanced dementia and substantial impaired communication: A cross-sectional analysis at baseline of a cluster randomized controlled trial. Pain Medicine, 18(9), 1649-1657. doi:10.1093/pm/pnw242

Malara, A., De Biase, G. A., Bettarini, F., Ceravolo, F., Di Cello, S., Garo, M., . . Rispoli, V. (2016). Pain assessment in elderly with behavioral and psychological symptoms of dementia. Journal of Alzheimers Disease, 50(4), 1217-1225. doi:10.3233/jad-150808

McDermott, O., Charlesworth, G., Hogervorst, E., Stoner, C., Moniz-Cook, E., Spector, A., . . Orrell, M. (2018). Psychosocial interventions for people with dementia: A synthesis of systematic reviews. Aging \& Mental Health, 1-11. doi:10.1080/13607863.2017.1423031

This article is protected by copyright. All rights reserved. 
McGuire, B. E., Nicholas, M. K., Asghari, A., Wood, B. M., \& Main, C. J. (2014). The effectiveness of psychological treatments for chronic pain in older adults: Cautious optimism and an agenda for research. Current Opinion in Psychiatry, 27(5), 380-384. doi:10.1097/YCO.0000000000000090

Melzack, R. (2001). Pain and the neuromatrix in the brain. Journal of Dental Education, 65(12), 13781382.

Mitchell, G., \& Agnelli, J. (2015). Non-pharmacological approaches to alleviate distress in dementia care. Nursing Standard, 30(13), 38-44. doi:10.7748/ns.30.13.38.s45

Moher, D., Liberati, A., Tetzlaff, J., \& Altman, D. G. (2009). Preferred reporting items for systematic reviews and meta-analyses: the PRISMA statement. British Medical Journal, 339. doi:10.1136/bmj.b2535

Moniz-Cook, E., Vernooij-Dassen, M., Woods, B., \& Orrell, M. (2011). Psychosocial interventions in dementia care research: The interdem manifesto. Aging \& Mental Health, 15(3), 283-290. doi:10.1080/13607863.2010.543665

Orgeta, V., Qazi, A., Spector, A., \& Orrell, M. (2015). Psychological treatments for depression and anxiety in dementia and mild cognitive impairment: Systematic review and meta-analysis. The British Journal of Psychiatry, 207(4), 293-298. doi: 210.1192/bjp.bp.1114.148130

Park, H., Chun, Y., \& Gang, M. S. (2015). Effects of the patient-centered environment program on behavioral and emotional problems in home-dwelling patients with dementia. Journal of Gerontological Nursing, 41(12), 40-48. doi:10.3928/00989134-20151111-02

Park, J., \& Hughes, A. K. (2012). Nonpharmacological approaches to the management of chronic pain in community-dwelling older adults: A review of empirical evidence. Journal of the American Geriatrics Society, 60(3), 555-568. doi:10.1111/j.1532-5415.2011.03846.x

This article is protected by copyright. All rights reserved. 
Pedersen, S. K. A. andersen, P. N., Lugo, R. G. andreassen, M., \& Sütterlin, S. (2017). Effects of music on agitation in dementia: A meta-analysis. Frontiers in Psychology, 8, 742. doi:10.3389/fpsyg.2017.00742

Pongan, E., Tillmann, B., Leveque, Y., Trombert, B., Getenet, J. C., Auguste, N., . . Rouch, I. (2017). Can musical or painting interventions improve chronic pain, mood, quality of life and cognition in patients with mild alzheimer's disease? Evidence from a randomized controlled trial. Journal of Alzheimer's Disease, 60(2), 663-677. doi:10.3233/JAD-170410

Rajkumar, A. P., Ballard, C., Fossey, J., Orrell, M., Moniz-Cook, E., Woods, R. T., . . Knapp, M. (2017). Epidemiology of pain in people with dementia living in care homes: Longitudinal course, prevalence and treatment implications. Journal of the American Medical Directors Association, 18(5), 453.e1-453.e6. doi:10.1016/j.jamda.2017.01.024

Rhoads, C. (2013). Mechanism of pain relief through tai chi and qigong. Journal of Pain \& Relief, 2(1), 115. doi:10.4172/2167-0846.1000115

Rodriguez-Mansilla, J., Gonzalez Lopez-Arza, M. V., Varela-Donoso, E., Montanero-Fernandez, J., Gonzalez Sanchez, B., \& Garrido-Ardila, E. M. (2015). The effects of ear acupressure, massage therapy and no therapy on symptoms of dementia: A randomized controlled trial. Clinical Rehabilitation, 29(7), 683-693. doi:10.1177/0269215514554240

Savvas, S., \& Gibson, S. (2015). Pain management in residential aged care facilities. Australian Family Physician, 44(4), 198-203.

Schofield, P. (2018). The assessment of pain in older people: UK national guidelines. Age Ageing, 47(suppl_1), i1-i22. doi:10.1093/ageing/afx192

Sloane, P. D., Hoeffer, B., Mitchell, C. M., McKenzie, D. A., Barrick, A. L., Rader, J., . . Zink, R. C. (2004). Effect of person-centered showering and the towel bath on bathing-associated aggression, agitation and discomfort in nursing home residents with dementia: $\mathrm{A}$

This article is protected by copyright. All rights reserved. 
randomized, controlled trial. Journal of the American Geriatrics Society, 52(11), 1795-1804.

doi:org/10.1111/j.1532-5415.2004.52501.x

Tederko, P., Krasuski, M., \& Szczypiorowska, B. G. (2014). Non-pharmacological pain therapies in long-term care residents: A systemic review of literature. Journal of Pain Management, 7(1), 37-46.

Tsai, P. F., Chang, J. Y., Beck, C., Kuo, Y. F., \& Keefe, F. J. (2013). A pilot cluster-randomized trial of a 20-week Tai Chi program in elders with cognitive impairment and osteoarthritic knee: Effects on pain and other health outcomes. Journal of Pain and Symptom Management, 45(4), 660669. doi:10.1016/j.jpainsymman.2012.04.009

Tsai, P. F., Chang, J. Y., Beck, C., Kuo, Y. F., Keefe, F. J., \& Rosengren, K. (2015). A supplemental report to a randomized cluster trial of a 20-week Sun-style Tai Chi for osteoarthritic knee pain in elders with cognitive impairment. Complementary Therapies in Medicine, 23(4), 570-576. doi:10.1016/j.ctim.2015.06.001

van Kooten, J., Smalbrugge, M., van der Wouden, J. C., Stek, M. L., \& Hertogh, C. M. P. M. (2017). Prevalence of pain in nursing home residents: The role of dementia stage and dementia subtypes. Journal of the American Medical Directors Association, 18(6), 522-527. doi:10.1016/j.jamda.2016.12.078

This article is protected by copyright. All rights reserved. 
Table 1 Summary of findings table for outcomes

Psychosocial interventions compared to control group for pain management in people with dementia

Patient or population: pain management in people with dementia

Setting: nursing home, community

Intervention: psychosocial interventions

Comparison: control group

\begin{tabular}{|c|c|c|c|}
\hline $\begin{array}{l}\text { Outcomes } \\
\text { (end of treatment) }\end{array}$ & $\begin{array}{l}\text { Anticipated absolute effects } \\
(95 \% \mathrm{Cl}) \\
\text { Scores with psychosocial intervention } \\
\text { compared with control group }\end{array}$ & $\begin{array}{l}\text { № of } \\
\text { participants } \\
\text { (studies) }\end{array}$ & $\begin{array}{l}\text { Certainty of the } \\
\text { evidence } \\
\text { (GRADE) }\end{array}$ \\
\hline \multicolumn{4}{|l|}{$\begin{array}{l}\text { Different outcome } \\
\text { measurement }\end{array}$} \\
\hline $\begin{array}{l}\text { Observational pain } \\
\text { follow up: range } 4 \\
\text { weeks to } 20 \text { weeks }\end{array}$ & $\begin{array}{l}\text { The SMD of observational pain score } \\
\text { was } 0.48 \text { lower ( } 0.85 \text { lower to } 0.10 \text { lower) }\end{array}$ & $\begin{array}{l}486 \\
\text { (8 RCTs) }\end{array}$ & $\begin{array}{l}\oplus \bigcirc \bigcirc \bigcirc \\
\text { VERY LOW }\end{array}$ \\
\hline $\begin{array}{l}\text { Self-reported pain } \\
\text { follow up: range } 12 \\
\text { weeks to } 20 \text { weeks }\end{array}$ & $\begin{array}{l}\text { The SMD of self-reported pain score } \\
\text { was } 0.27 \text { lower ( } 0.57 \text { lower to } 0.03 \\
\text { higher) }\end{array}$ & $\begin{array}{l}114 \\
\text { (2 RCTs) }\end{array}$ & $\begin{array}{l}\oplus \oplus \oplus \bigcirc \\
\text { MODERATE }\end{array}$ \\
\hline \multicolumn{4}{|l|}{$\begin{array}{l}\text { Different types of } \\
\text { interventions }\end{array}$} \\
\hline $\begin{array}{l}\text { - Sensory stimulation } \\
\text { follow up: range } 4 \\
\text { weeks to } 12 \text { weeks }\end{array}$ & $\begin{array}{l}\text { The SMD of observational pain } \\
\text { score was } 0.58 \text { lower } \\
\text { (0.99 lower to } 0.17 \text { lower) }\end{array}$ & $\begin{array}{l}330 \\
\text { (6 RCTs) }\end{array}$ & $\begin{array}{l}\oplus \bigcirc \bigcirc \bigcirc \\
\text { VERY LOW }\end{array}$ \\
\hline $\begin{array}{l}\text { - Physical activity } \\
\text { follow up: range } 4 \\
\text { weeks to } 20 \text { weeks }\end{array}$ & $\begin{array}{l}\text { The SMD of observational pain } \\
\text { score was } 0.24 \text { lower } \\
\text { (1.06 lower to } 0.59 \text { higher) }\end{array}$ & $\begin{array}{l}156 \\
\text { (2 RCTs) }\end{array}$ & $\begin{array}{l}\oplus \oplus \bigcirc \bigcirc \\
\text { LOW }\end{array}$ \\
\hline
\end{tabular}

Different format of interventions

This article is protected by copyright. All rights reserved. 
Table 1 Summary of findings table for outcomes

Psychosocial interventions compared to control group for pain management in people with dementia

Patient or population: pain management in people with dementia

Setting: nursing home, community

Intervention: psychosocial interventions

Comparison: control group

\begin{tabular}{|c|c|c|c|}
\hline $\begin{array}{l}\text { Outcomes } \\
\text { (end of treatment) }\end{array}$ & $\begin{array}{l}\text { Anticipated absolute effects } \\
(95 \% \mathrm{Cl}) \\
\text { Scores with psychosocial intervention } \\
\text { compared with control group }\end{array}$ & $\begin{array}{l}\text { № of } \\
\text { participants } \\
\text { (studies) }\end{array}$ & $\begin{array}{l}\text { Certainty of the } \\
\text { evidence } \\
\text { (GRADE) }\end{array}$ \\
\hline $\begin{array}{l}\text { - Group intervention } \\
\text { follow up: range } 12 \\
\text { weeks to } 20 \text { weeks }\end{array}$ & $\begin{array}{l}\text { The SMD of observational pain } \\
\text { score was } 0.27 \text { lower } \\
\text { (1.06 lower to } 0.53 \text { higher) }\end{array}$ & $\begin{array}{l}114 \\
\text { (2 RCTs) }\end{array}$ & $\begin{array}{l}\oplus \oplus \bigcirc \bigcirc \\
\text { LOW }\end{array}$ \\
\hline $\begin{array}{l}\text { - Individual intervention } \\
\text { follow up: range } 4 \\
\text { weeks to } 12 \text { weeks }\end{array}$ & $\begin{array}{l}\text { The SMD of observational pain } \\
\text { score was } 0.55 \text { lower } \\
\text { (1.01 lower to } 0.09 \text { lower) }\end{array}$ & $\begin{array}{l}372 \\
\text { (6 RCTs) }\end{array}$ & $\begin{array}{l}\oplus \bigcirc \bigcirc \bigcirc \\
\text { VERY LOW }\end{array}$ \\
\hline Pain medication & $\begin{array}{l}\text { The mean change of medication was } \\
\text { higher }-684.52(-2005.70,636.66)\end{array}$ & $\begin{array}{l}55 \\
(1 \mathrm{RCT})\end{array}$ & - \\
\hline Adverse events & $\begin{array}{l}\text { Five studies reported no adverse events } \\
\text { during the study period. }\end{array}$ & $\begin{array}{l}234 \\
\text { (5 RCTs) }\end{array}$ & $\begin{array}{l}\oplus \bigcirc \bigcirc \bigcirc \\
\text { VERY LOW }\end{array}$ \\
\hline
\end{tabular}

*The risk in the intervention group (and its $95 \%$ confidence interval) is based on the assumed risk in the comparison group and the relative effect of the intervention (and its $95 \% \mathrm{Cl}$ ).

Cl: Confidence interval; SMD: Standardised mean difference.

This article is protected by copyright. All rights reserved. 
Table 1 Summary of findings table for outcomes

Psychosocial interventions compared to control group for pain management in people with dementia

Patient or population: pain management in people with dementia

Setting: nursing home, community

Intervention: psychosocial interventions

Comparison: control group

\begin{tabular}{l|l|l|l}
\hline $\begin{array}{l}\text { Outcomes } \\
\text { (end of treatment) }\end{array}$ & $\begin{array}{l}\text { Anticipated absolute effects } \\
(95 \% \mathrm{CI})\end{array}$ & $\begin{array}{l}\text { № of } \\
\text { participants } \\
\text { (studies) }\end{array}$ & $\begin{array}{l}\text { Certainty of the } \\
\text { evidence } \\
\text { (GRADE) }\end{array}$ \\
$\begin{array}{l}\text { Scores with psychosocial intervention } \\
\text { compared with control group }\end{array}$ & \\
\hline
\end{tabular}

GRADE Working Group grades of evidence

High certainty: We are very confident that the true effect lies close to that of the estimate of the effect

Moderate certainty: We are moderately confident in the effect estimate: The true effect is likely to be close to the estimate of the effect, but there is a possibility that it is substantially different Low certainty: Our confidence in the effect estimate is limited: The true effect may be substantially different from the estimate of the effect

Very low certainty: We have very little confidence in the effect estimate: The true effect is likely to be substantially different from the estimate of effect

This article is protected by copyright. All rights reserved. 


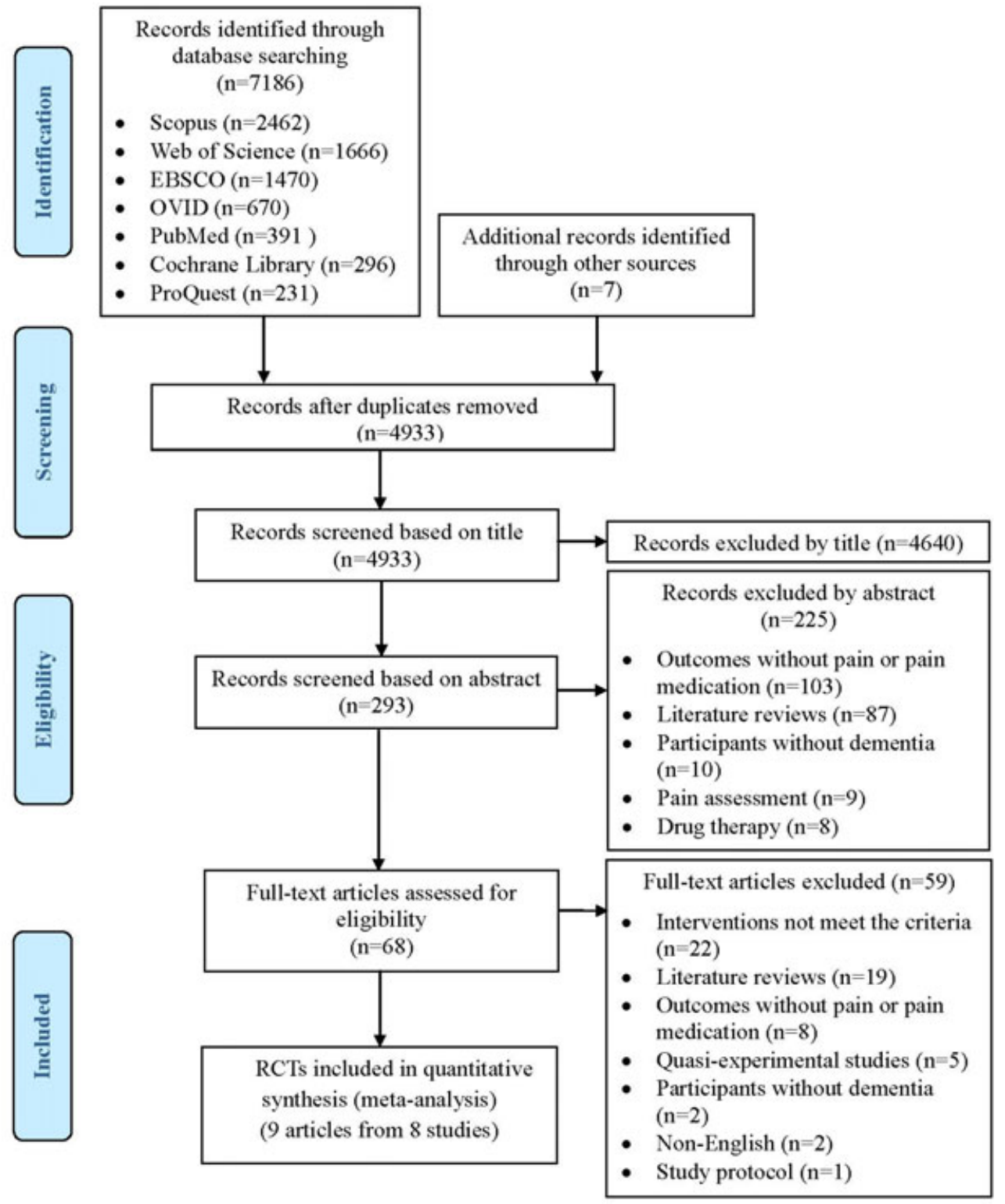

FIGURE 1 Study flow diagram

This article is protected by copyright. All rights reserved. 

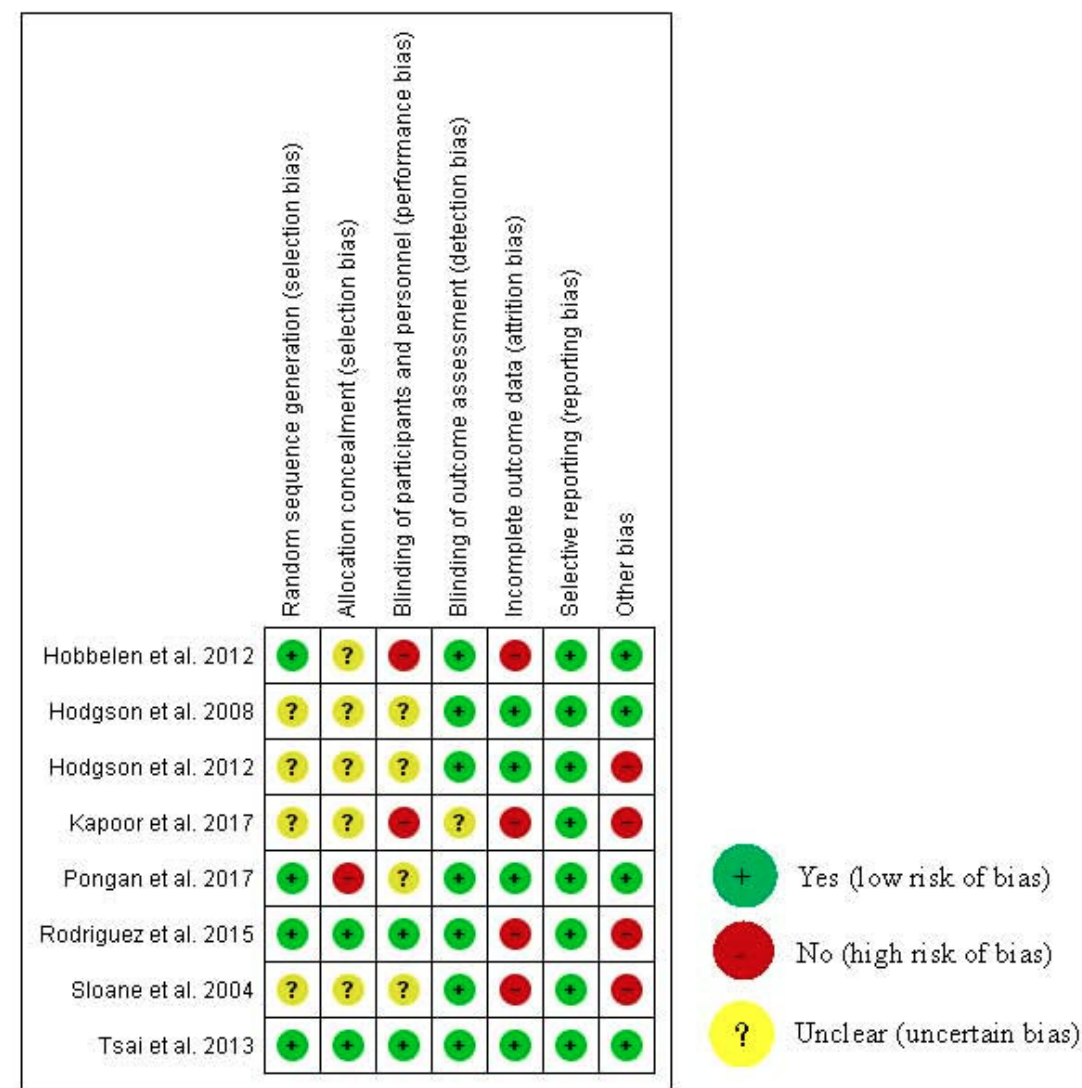

FIGURE 2 Risk of bias summary

This article is protected by copyright. All rights reserved. 


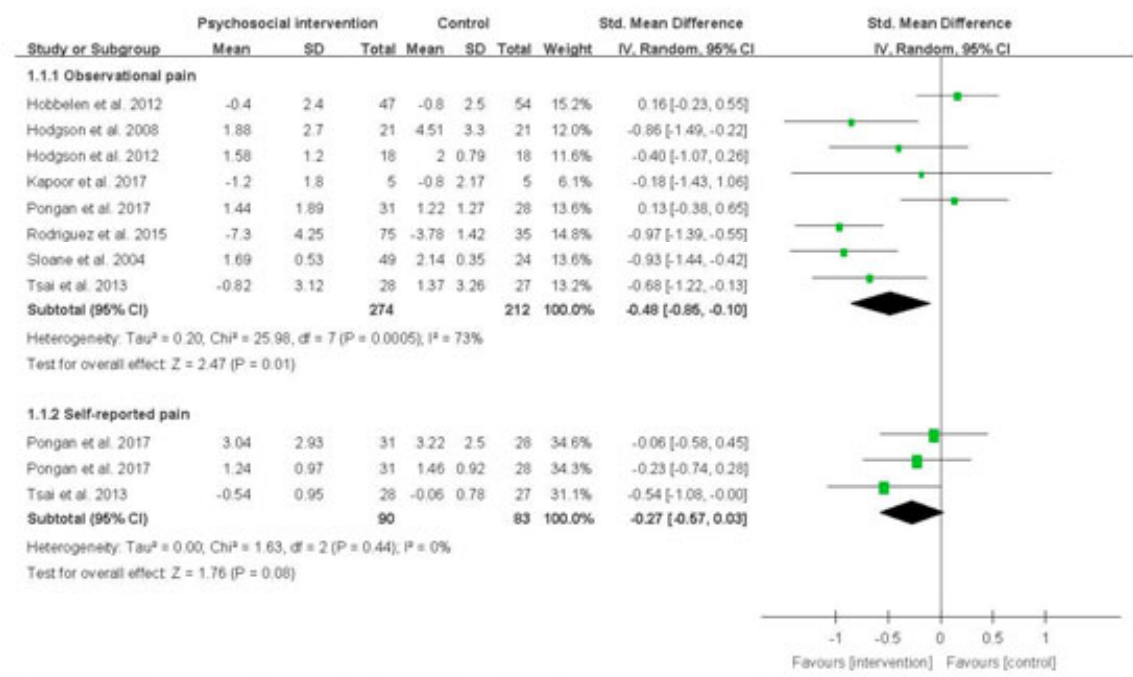

FIGURE 3 Subgroup analysis: different pain measurements

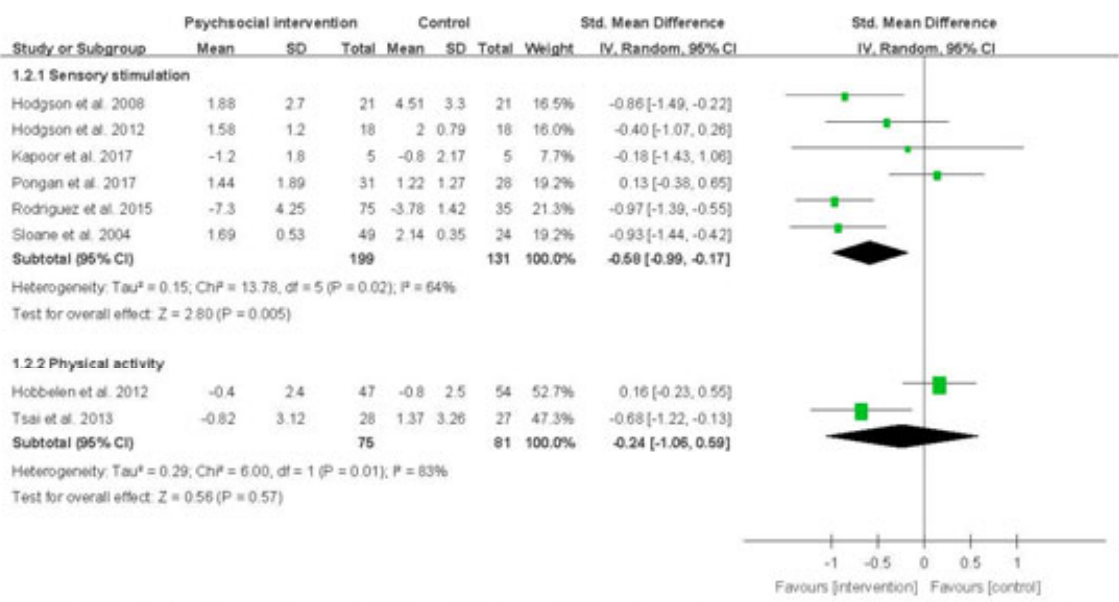

FIGURE 4 Subgroup analysis: different types of psychosocial interventions on observational pain

This article is protected by copyright. All rights reserved. 


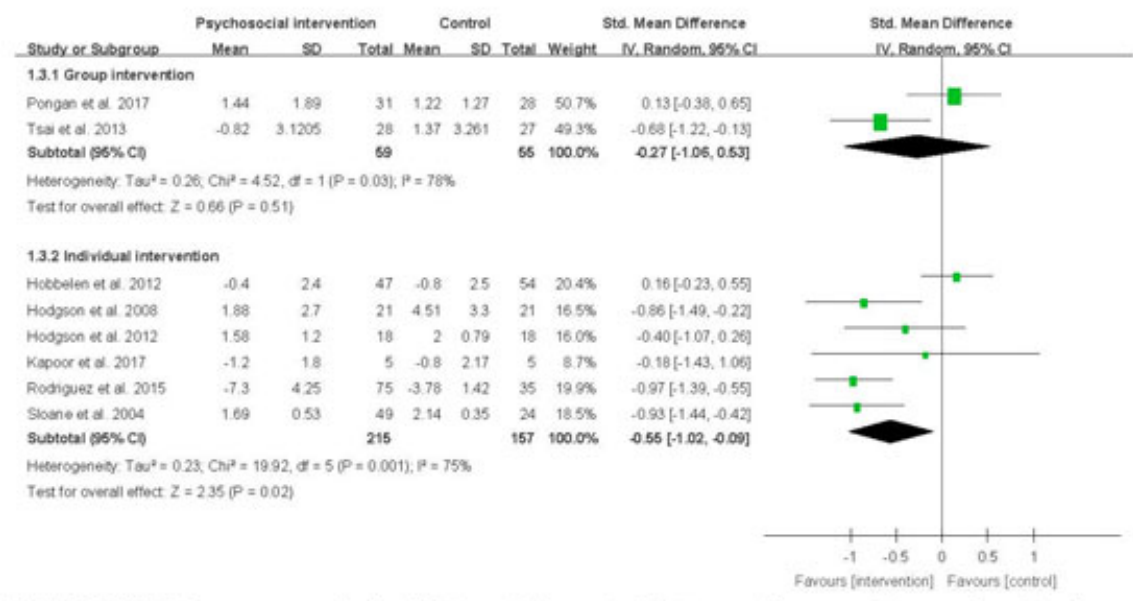

FIGURE 5 Subgroup analysis: different format of interventions on observational pain

This article is protected by copyright. All rights reserved. 